\title{
Scratching the surface - tobacco-induced bacterial biofilms
}

\author{
Justin A Hutcherson ${ }^{1}$, David A Scott ${ }^{2^{*}}$ and Juhi Bagaitkar ${ }^{3}$
}

\begin{abstract}
Individual environmental factors, such as iron, temperature and oxygen, are known to have a profound effect on bacterial phenotype. Therefore, it is surprising so little known is about the influence of chemically complex cigarette smoke on bacterial physiology. Recent evidence has demonstrated that tobacco smoke and components alter the bacterial surface and promote biofilm formation in several important human pathogens, including Staphylococcus aureus, Streptococcus mutans, Klebsiella pneumonia, Porphyromonas gingivalis and Pseudomonas aeruginosa. The mechanisms underlying this phenomenon and the relevance to increased susceptibility to infectious disease in smokers and to treatment are reviewed.
\end{abstract}

Keywords: Bacteria, Biofilms, Cigarette smoking, Infectious diseases, Outer membrane, Tobacco

\section{Introduction}

The numbers of smokers and, subsequently, tobaccoinduced deaths continues to rise globally. In addition to cancers, chronic lung disease and cardiovascular complications, cigarette use is a major risk factor for multiple bacterial infections. These include biofilm-associated diseases, such as community-acquired pneumonia, otitis media, vaginosis and chronic periodontitis [1]. While there has been considerable focus on the mechanisms by which smoking dysregulates the immune system $[2,3]$, little information is available as to how smoking influences the actual bacteria that cause disease. It is clear, however, that many bacteria exhibit a high degree of tolerance to cigarette smoke and smoke components [4-9], while it has been known for some considerable time that tobacco components can even promote the growth of some pathogenic bacteria, such as Haemophilus influen$z a e$ [10]. This review summarizes the available literature on tobacco smoke augmentation of biofilm formation by several important human pathogens. While it is apparent that we are only scratching the surface, mechanistically, potential explanations for smoke-induced biofilm enhancement are discussed.

\footnotetext{
* Correspondence: david.scott@louisville.edu

${ }^{2}$ Oral Immunology and Infectious Diseases, University of Louisville, 501 South Preston Street, Louisville, KY 40292, USA

Full list of author information is available at the end of the article
}

\section{Methods}

\section{Search strategy}

Pubmed was investigated on 5 May 2014 and again on manuscript revision according to the following search strategies. [\#1 (tobacco OR cigar* OR smok* OR nicotine) AND biofilm]; [\#1 AND \#2 (bacter*) AND coloniz*]; [\#1 AND \#2 AND membrane]; [\#1 AND \#2 AND ultrastructure]; [\#1 AND \#2 AND LPS]; [\#1 AND \#2 AND fimbria*"; [\#1 AND \#2 AND flagella]; [\#1 AND \#2 AND lipoteichoic]; [\#1 AND \#2 AND adhesion]; [\#1 AND \#2 AND adhesin]; and [\#1 AND \#2 AND peptidoglycan]. Data identified as generated by the tobacco industry was excluded $a$ priori.

\section{Results and discussion}

Biofilm formation and bacterial survival

Biofilms are dense, surface-attached communities of bacteria or fungal species enclosed within a microbialderived matrix that facilitates colonization and survival. The chemical composition, complexity and microbial diversity of a biofilm can vary relative to its environment. However the dynamics of biofilm formation can be generalized into three interlinked stages.

Attachment of planktonic bacteria to abiotic or biotic surfaces comprises the first stage of biofilm formation. Attachment occurs after detection of optimal nutrient or host-derived metabolite concentrations, $\mathrm{pH}$, temperature and other favorable environmental signals [11]. Microbe- 
derived adhesive proteins and adhesive organelles, like fimbriae and pili, facilitate attachment of planktonic bacteria to the tissue or abiotic surface. The expression profiles of genes involved in bacterial motility, extracellular matrix formation, quorum sensing, chemotaxis and posttranscriptional regulatory circuits converge to promote colonization and establishment of biofilms [12,13]. Significant human pathogens, including Pseudomonas aeruginosa, Vibrio cholerae and Escherichia coli, all undergo extensive morphological and transcriptional changes to attach and colonize the host [12].

Following initial attachment, secondary species may bind to these early colonizers, increasing biofilm complexity. During the second stage of biofilm formation, cellular replication, synergistic intra- and inter-species interactions promote microcolony formation and the deposition of an extracellular matrix. Microcolonies grow as a direct consequence of bacterial replication and aggregation [14]. The extracellular matrix consists of exopolysaccharies, extracellular DNA, RNA, matrix-associated proteins and adhesins synthesized by the colonizing bacteria which promotes cellto-cell adhesion and further stabilizes biofilm architecture. There may be several niches or microenvironments generated within a biofilm due, for example, to nutrient, oxygen and $\mathrm{pH}$ gradients. These gradients create selective pressure and can also enhance the pathogenic potential of an organism. The extracellular matrix also presents a diffusion barrier for most antimicrobial peptides and antimicrobial compounds.

Biofilms have been estimated to account for $65 \%$ or more of all microbial infections in humans [15]. This has critical implications to disease prevention as such microbial communities provide several advantages to the bacteria, such as (i) enhanced evolution through the sharing of genetic material, including antibiotic resistance and other virulence factor genes; (ii) protection from antibiotics; (iii) shielding from critical components of the immune response, including the complement/ antibody system and phagocytosis; and (iv) the potential to further colonize the host upon shedding from the biofilm [15-18]. Given their high degree of resistance to current anti-microbial compounds, biofilms play a significant role in the pathogenesis of many chronic human infections, such as cystic fibrosis, bacterial endocarditis and periodontal diseases [19]. Furthermore, biofilms can prolong inflammation and delay resolution in chronic wound infections [20]. Several recent reviews of infectious biofilms are available [15,18,21-24].

\section{Tobacco smoke promotes biofilm formation}

Simple environmental stimuli, including temperature, $\mathrm{pH}$ and the availability of iron, have a major influence on the bacterial transcriptome and influence biofilm formation in, for example, Pseudomonas aeruginosa, Klebsiella pneumonia, Porphyromonas gingivalis, and the melioidosis pathogen, Burkholderia pseudomallei [25-28]. It is perhaps not surprising, then, that cigarette smoke, which contains thousands of chemicals, can exert a profound influence on bacterial physiology and biofilm formation.

The evidence that tobacco promotes bacterial biofilms in multiple pathogenic bacteria is growing, as summarized in Table 1 along with their associated diseases. The most extensive study to date is by Goldstein-Daruech et al. [29], who demonstrated that acute cigarette smoke exposure significantly increased biofilm formation in $75 \%(12 / 16)$ of clinical isolates of various species from smokers with chronic rhinosinusitis but in $0 \%$ (0 of 18) of isolates from nonsmokers. Importantly, such enhanced biofilm formation was reversible on removal of the cigarette smoke stimulus. An overall biofilm index for smokers and non-smokers is reproduced from the Goldstein-Daruech study in Figure 1.

Mechanisms of tobacco smoke-enhanced biofilm formation We are only beginning to understand how tobacco smoke may enhance microbial biofilms. However, it is clear that the first step in biofilm formation is adherence to a stratum, be that epithelial or endothelial cells; extant colonized bacteria; or to a sugar or protein. Tobacco smoke augments binding of Streptococcus pneumonia to pulmonary epithelial cells by inducing eukaryotic platelet-activating factor receptor (PAF-R) expression, which interacts with phosphorylcholine on the bacterial cell wall [37]. In P. gingivalis, the major fimbrial protein, FimA, is upregulated, which aids adhesion by binding to the glyceraldehyde 3-phosphate dehydrogenase (GAPDH) surface protein of the primary periodontal colonizer, Streptococcus gordonii [31]. The predominant nicotine metabolite, cotinine, has been reported to increase P. gingivalis adhesion to epithelial cell monolayers [4]. Cigarette smoke extract (CSE) also appears to promote adhesion of Aggregatibacter actinomycetemcomitans, an oral biofilm dweller associated with a localized, aggressive form of periodontal disease, to epithelial cells [38].

Sortase A (cell surface protein P1) is employed by the cariogenic agent, Streptococcus mutans, and other Grampositive bacteria, to facilitate the localization of specific, LPXTGX-containing proteins to the microbial surface. One such protein is the salivary agglutinin-binding, biofilm promoting antigen I/II. It has recently been shown that the tobacco alkaloid, nicotine, upregulates the surface expression of antigen I/II by $S$. mutans and, subsequently, enhances biofilm formation [9]. The authors [9] suggest that this nicotine-enhanced biofilm formation helps explain the increased number of teeth with carious lesions found in smokers compared to non-smokers [39]. Indeed, nicotine has also been shown to enhance dual species $S$. mutans biofilm formation with Streptococcus sanguinis [8]. 
Table 1 Tobacco augments biofilm formation in multiple human pathogens

\begin{tabular}{|c|c|c|c|}
\hline Bacterium (Gram) & Disease & Stimulus $^{1}$ & Study \\
\hline Klebsiella pneumonia (-) & Chronic rhinosinusitis isolate & Whole smoke & Goldstein-Daruech et al. 2011 [29] \\
\hline \multirow[t]{2}{*}{ Pseudomonas aeruginosa $(-)$} & \multirow{2}{*}{$\begin{array}{l}\text { Nosocomial infections; UTI; respiratory } \\
\text { infections including pneumonia }\end{array}$} & \multirow[t]{2}{*}{ Whole smoke } & Antunes 2012 [30] \\
\hline & & & Goldstein-Daruech et al. 2011 [29] \\
\hline Porphyromonas gingivalis (-) & Chronic periodontitis & CSE & Bagaitkar et al. 2009, $2011[1,31]^{2}$ \\
\hline Proteus vulgaris (-) & Chronic rhinosinusitis isolate & Whole smoke & Goldstein-Daruech et al. 2011 [29] \\
\hline \multirow[t]{2}{*}{ Staphylococcus aureus (+) } & \multirow{2}{*}{$\begin{array}{l}\text { Nosocomial infections; endocarditis; osteomyelitis; } \\
\text { respiratory infections }\end{array}$} & \multirow[t]{2}{*}{ CSE } & Kulkarni 2013 [32] \\
\hline & & & Goldstein-Daruech et al. 2011 [29] \\
\hline \multirow[t]{3}{*}{ Streptococcus pneumoniae (+) } & \multirow[t]{3}{*}{ Pneumonia, bronchitis; endocarditis; meningitis } & \multirow[t]{3}{*}{$\operatorname{CSC}$} & Cockeran et al. 2014 [33] \\
\hline & & & Mutepe et al. 2012 [34] \\
\hline & & & Goldstein-Daruech et al. 2011 [29] \\
\hline \multirow[t]{3}{*}{ Streptococcus mutans $(+)$} & \multirow[t]{3}{*}{ Dental caries } & \multirow[t]{3}{*}{ Nicotine, CSC } & Li $2014[8]^{3}$ \\
\hline & & & Huang et al. 2012 [35] \\
\hline & & & Baboni 2010 [36] \\
\hline
\end{tabular}

${ }^{1}$ See references for precise methods of whole smoke exposure, CSE (cigarette smoke extract) or CSC (cigarette smoke condensate) preparation and of biofilm quantification.

Dual species biofilms with S. gordonii ${ }^{2}$ or S. sanguinis ${ }^{3}$.

Cigarette smoke exposure also leads to increased biofilm formation in the key human pathogen, Staphylococcus aureus, which can cause, for example, skin infections, pneumonia, endocarditis, and septic shock [32]. The staphylococcal genes, accessory regulator $\mathrm{A}(\operatorname{sar} A)$ and required for biofilm formation $(r b f)$, which encode biofilm enhancing proteins, and fibronectin binding protein $\mathrm{A}$ $(f n b A)$, whose gene product facilitates bacterial adhesion, are upregulated by cigarette smoke. The accessory gene regulator (agr) family of genes is involved in quorum

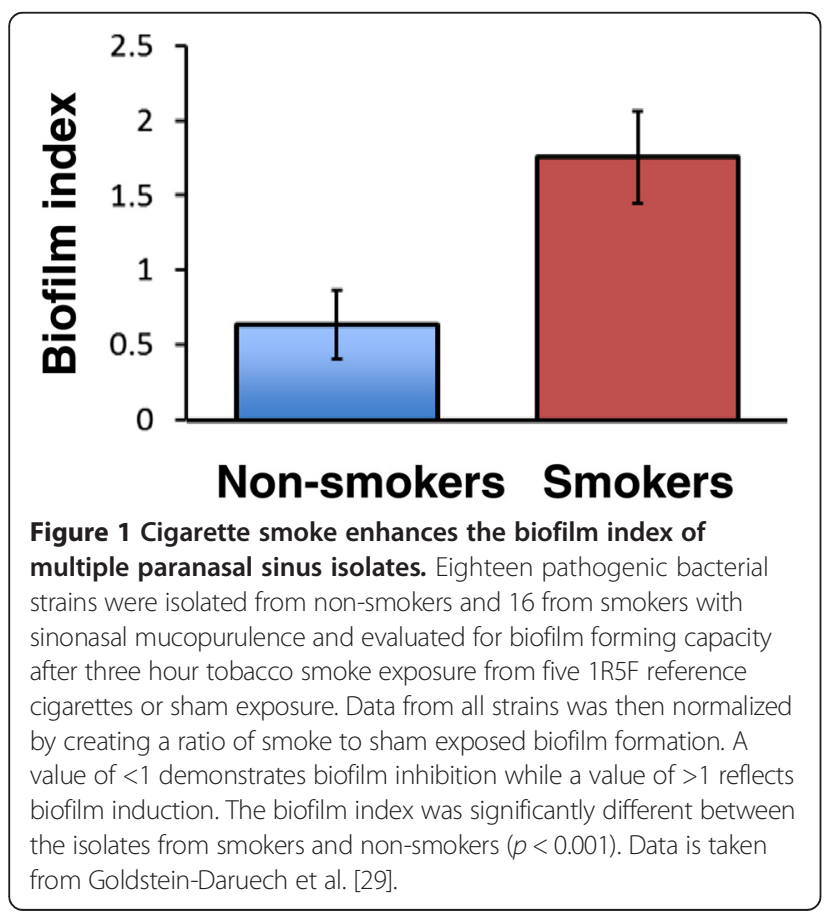

sensing which controls bacterial dispersal. agrC activity is suppressed by cigarette smoke. Cigarette smokeenhanced biofilm formation in $S$. aureus is abrogated by pre-treatment with the antioxidant, $N$-acetyl cysteine, suggesting that smoke-induced $S$. aureus biofilm formation is oxidant-dependent [32].

Whole cigarette smoke exposure has been reported to increase biofilm formation in other pathogens but, again, there is little mechanistic insight. Several biofilm promoting $P$. aeruginosa genes (pilF, flgK) are induced by cigarette smoke, while the quorum sensing gene, $r h l A$, is suppressed [30]. Cigarette smoke condensate has also been shown to increase Streptococcus pneumoniae biofilm formation associated with a reduced production of pneumolysin, a key mediator of $S$. pneumoniae-induced inflammation [34].

\section{Tobacco smoke and oral biofilms}

Presumably due to ubiquity of dental plaque, the high prevalence of bacteria-induced oral diseases, and ease of access to clinical samples, our knowledge of the influence of smoking on biofilms is broadest for those found in periodontal tissues. Oral biofilms are complex and colonize both supra- and sub-gingival regions of the oral cavity and their composition can correlate with increased severity of periodontal disease [40].

Chronic periodontitis is a tobacco-induced and/or exacerbated disease [41]. Multiple studies have established that smoking alters the bacterial composition of dental plaque, with several important periodontal pathogens including Treponema denticola, Fusobacterium nucleatum and $P$. gingivalis, over-represented in cigarette users, relative to non-smokers [1,41-45]. Commensal 

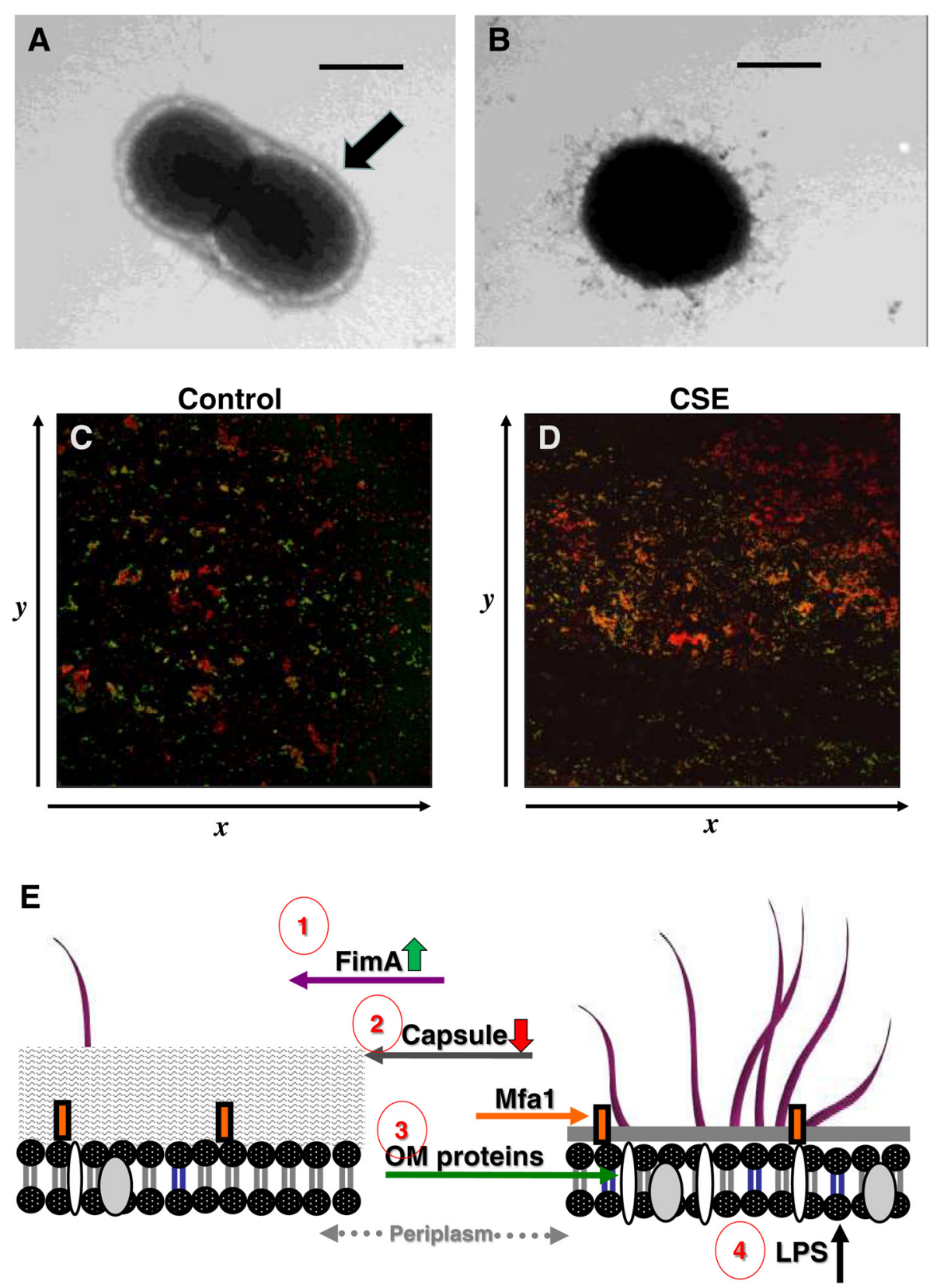

\section{NORMAL}

\section{SMOKE-EXPOSED}

Figure 2 Cigarette smoke extract alters key $P$. gingivalis surface molecules and enhances biofilm formation. Representative transmission electron microscope images of $P$. gingivalis grown in control medium (A) or CSE-conditioned medium (B) are shown. The black arrow indicates the $P$. gingivalis capsule, which is greatly reduced in the presence of CSE. Images and data taken from Bagaitkar et al. [6]. (C, D) S. gordonii cells (hexidium iodide-labeled, red) were placed on a saliva-coated coverglass in a flow cell. P. gingivalis cells (FITC conjugated anti-P. gingivalis IgG-labeled, green) were passed through. P. gingivalis-S. gordonii microcolonies (yellow) were visualized by confocal microscopy. The number of dual species microcolonies formed was significantly greater in the CSE-exposed cells compared to the controls $(p<0.01)$. Observation first published in [31] but data previously unpublished in this form. (E) A model of cigarette smoke extract-induced alterations to the surface of the periodontal pathogen, P. gingivalis, is presented. (1) Surface expression of the major fimbrial protein (FimA), but not the minor fimbrial antigen (Mfa1), is upregulated [6]. (2) At the same time, the highly pro-inflammatory capsule is inhibited by CSE, increasing fimbrial protein bioavailability. (3) Multiple outer membrane proteins are upregulated upon cigarette smoke exposure, including the highly antigenic RagB protein [6]. The biological significance of CSE-induced alterations to the membrane proteome is currently under investigation. (4) While we have not examined P. gingivalis directly, the LPS profile in the saliva of smokers, compared to that of non-smokers, exhibits altered 3-OH fatty acid content derived from overall oral microbiome [55]. 
species, such as Streptococcus species may be in higher abundance in non-smokers compared to smokers [44]. Interestingly, smokers who quit show a reversion to a healthier biofilm composition after 6 months [46].

Increased prevalence of $P$. gingivalis, the laboratory workhorse of periodontal pathogens, has been repeatedly shown in smokers [47-50]. Furthermore, $P$. gingivalis is found in significantly higher numbers in smokers than non-smokers and infection is more persistent in smokers compared to non-smokers $[41,51]$. With this in mind, we have examined the mechanisms by which tobacco smoke augments $P$. gingivalis biofilm formation. These are summarized in Figure 2. CSE significantly influences the expression of $6.8 \%$ of the $P$. gingivalis genome, as determined by whole genome arrays, with several genes in the $P$. gingivalis capsular operon significantly suppressed [6]. Transmission electron microscopy confirmed that CSE exposure suppresses capsule formation in $P$. gingivalis at the ultrastructural level (Figure 2A and $\mathrm{B})$. Nicotine alone has also been reported to influence extracellular polysaccharide production in $S$. mutans and S. sanguinis, partly explaining enhanced interactions between these two bacteria [8]. Furthermore, CSE promotes $P$. gingivalis-Streptococcus gordonii dual species biofilm formation [52], as shown in Figure 2C and D. Surface expression of the major fimbrial protein (FimA), but not the minor fimbrial antigen (Mfa1), is upregulated by CSE [6]. This promotes interactions with the early dental plaque colonizer, S. gordonii, enhancing biofilm formation [31]. Indeed, FimA mutants do not form biofilms [53]. Increased FimA production may also aid $P$. gingivalis survival by suppressing the TLR-mediated inflammatory response to this pathogen [31]. As noted earlier, the highly pro-inflammatory capsule is inhibited by CSE, which increases fimbrial protein bioavailability. Multiple outer membrane proteins are upregulated upon cigarette smoke exposure, including the highly antigenic RagB protein [6]. The biological significance of CSEinduced alterations to the membrane proteome is currently under investigation. $P$. gingivalis produces several types of lipopolysaccharide (LPS) that comprise the external leaflet of the Gram-negative outer membrane. The inflammatory potential of these LPS isoforms is highly variable. Penta-acylated lipid A isoforms efficiently induce inflammation upon engagement of TLR4 on innate immune cells while tetra-acylated lipid A isoforms are antagonistic [54]. In addition to acylation, the length of lipid A 3-OH fatty acid chains also influences inflammatory capacity. While we have not examined $P$. gingivalis individually, lipid A-derived 3-OH fatty acid profiles in the saliva of smokers are altered, compared to that of non-smokers, and are consistent with an oral biofilm of reduced inflammatory potential [55]. A model of CSE-induced alterations to $P$. gingivalis physiology is presented in Figure $2 \mathrm{E}$.

\section{Conclusions}

Since the discovery in 2010 that cigarette smoke extract augments biofilm formation in the oral pathogen, $P$. gingivalis [52], it has become apparent that smoking promotes bacterial adhesion and biofilm formation in several other key pathogens, including $S$. mutans, $S$. aureus, $P$. aeruginosa and S. pneumoniae. Enhanced bacterial evolution, including the emergence of antibiotic resistance, protection from antibiotics and other antimicrobials, immune response shielding and the increased potential for secondary colonization each have clear implications to disease treatment for the present and the future. However, it is clear that when it comes to understanding the underlying mechanisms we are currently just "scratching the surface".

\section{Competing interests}

The authors declare that they have no competing interests.

\section{Authors' contributions}

DAS, JB and $\mathrm{JH}$ drafted this review article. All authors read and approved the final manuscript.

\section{Acknowledgements}

Funding from NIDCR (R01DE017680, DAS) is gratefully acknowledged.

\section{Author details}

${ }^{1}$ Departments of Microbiology and Immunology, University of Louisville, Louisville, USA. ${ }^{2}$ Oral Immunology and Infectious Diseases, University of Louisville, 501 South Preston Street, Louisville, KY 40292, USA. ${ }^{3}$ Pediatrics, Washington University School of Medicine, Saint Louis, MO, USA.

Received: 15 July 2014 Accepted: 8 December 2014

Published online: 10 February 2015

\section{References}

1. Bagaitkar J, Demuth DR, Scott DA. Tobacco use increases susceptibility to bacterial infection. Tob Induc Dis. 2008;4:12.

2. Rom O, Avezov K, Aizenbud D, Reznick AZ. Cigarette smoking and inflammation revisited. Respir Physiol Neurobiol. 2013;187(1):5-10.

3. Stampfli MR, Anderson GP. How cigarette smoke skews immune responses to promote infection, lung disease and cancer. Nat Rev Immunol. 2009:9(5):377-84.

4. Cogo K, Calvi BM, Mariano FS, Franco GC, Gonçalves RB, Groppo FC. The effects of nicotine and cotinine on Porphyromonas gingivalis colonisation of epithelial cells. Arch Oral Biol. 2009;54(11):1061-7.

5. Cogo K, Montan MF, Bergamaschi Cde C, D Andrade E, Rosalen PL, Groppo FC. In vitro evaluation of the effect of nicotine, cotinine, and caffeine on oral microorganisms. Can J Microbiol. 2008;54(6):501-8.

6. Bagaitkar J, Williams LR, Renaud DE, Bemakanakere MR, Martin M, Scott DA et al. Tobacco-induced alterations to Porphyromonas gingivalis-host interactions. Environ Microbiol. 2009;11(5):1242-53.

7. Huang J, Carney BF, Denny TP, Weissinger AK, Schell MA. A complex network regulates expression of eps and other virulence genes of Pseudomonas solanacearum. J Bacteriol. 1995;177(5):1259-67.

8. Li M, Huang R, Zhou X, Zhang K, Zheng X, Gregory RL. Effect of nicotine on dual-species biofilms of Streptococcus mutans and Streptococcus sanguinis. FEMS Microbiol Lett. 2014;350(2):125-32.

9. Li MY, Huang RJ, Zhou XD, Gregory RL. Role of sortase in Streptococcus mutans under the effect of nicotine. Int J Oral Sci. 2013;5(4):206-11.

10. Roberts $D$, Cole P. Effect of tobacco and nicotine on growth of Haemophilus influenzae in vitro. J Clin Pathol. 1979;32(7):728-31.

11. Petrova OE, Sauer K. Sticky situations: key components that control bacterial surface attachment. J Bacteriol. 2012;194(10):2413-25.

12. OToole G, Kaplan HB, Kolter R. Biofilm formation as microbial development. Annu Rev Microbiol. 2000;54:49-79.

13. Martinez $L C$, Vadyvaloo V. Mechanisms of post-transcriptional gene regulation in bacterial biofilms. Front Cell Infect Microbiol. 2014;4:38. 
14. Johnson LR. Microcolony and biofilm formation as a survival strategy for bacteria. J Theor Biol. 2008;251(1):24-34.

15. de la Fuente-Núñez C, Reffuveille F, Fernández L, Hancock RE. Bacterial biofilm development as a multicellular adaptation: antibiotic resistance and new therapeutic strategies. Curr Opin Microbiol. 2013;16(5):580-9.

16. Marks LR, RM Reddinger, and AP Hakansson. High levels of genetic recombination during nasopharyngeal carriage and biofilm formation in Streptococcus pneumoniae. MBio. 2012;3(5). http://www.ncbi.nlm.nih.gov/ pubmed/23015736.

17. Marks LR, Parameswaran Gl, Hakansson AP. Pneumococcal interactions with epithelial cells are crucial for optimal biofilm formation and colonization in vitro and in vivo. Infect Immun. 2012;80(8):2744-60.

18. Hall-Stoodley L, Stoodley P. Evolving concepts in biofilm infections. Cell Microbiol. 2009;11(7):1034-43.

19. Parsek MR, Singh PK. Bacterial biofilms: an emerging link to disease pathogenesis. Annu Rev Microbiol. 2003;57:677-701.

20. Zhao G, Usui ML, Lippman SI, James GA, Stewart PS, Fleckman P, et al. Biofilms and Inflammation in Chronic Wounds. Adv Wound Care (New Rochelle). 2013;2(7):389-99.

21. Belas R. Biofilms, flagella, and mechanosensing of surfaces by bacteria. Trends Microbiol. 2014. http://www.ncbi.nlm.nih.gov/pubmed/24894628

22. Bjarnsholt T, Alhede M, Alhede M, Eickhardt-Sørensen SR, Moser C, Kühl M, et al. The in vivo biofilm. Trends Microbiol. 2013;21(9):466-74.

23. Sun F, Qu F, Ling Y, Mao P, Xia P, Chen H, et al. Biofilm-associated infections: antibiotic resistance and novel therapeutic strategies. Future Microbiol. 2013;8(7):877-86

24. Van Acker H, Van Dijck P, Coenye T. Molecular mechanisms of antimicrobial tolerance and resistance in bacterial and fungal biofilms. Trends Microbiol. 2014:22(6):326-33.

25. Banin E, Vasil ML, Greenberg EP. Iron and Pseudomonas aeruginosa biofilm formation. Proc Natl Acad Sci U S A. 2005;102(31):11076-81.

26. Hostacka A, Ciznar I, Stefkovicova M. Temperature and $\mathrm{pH}$ affect the production of bacterial biofilm. Folia Microbiol (Praha). 2010;55(1):75-8.

27. Ramli NS, Eng Guan C, Nathan S, Vadivelu J. The effect of environmental conditions on biofilm formation of Burkholderia pseudomallei clinical isolates. PLoS One. 2012;7(9):e44104.

28. Wakabayashi H, Yamauchi K, Kobayashi T, Yaeshima T, Iwatsuki K, Yoshie H. Inhibitory effects of lactoferrin on growth and biofilm formation of Porphyromonas gingivalis and Prevotella intermedia. Antimicrob Agents Chemother. 2009;53(8):3308-16.

29. Goldstein-Daruech N, Cope EK, Zhao KQ, Vukovic K, Kofonow JM, Doghramji $L$, et al. Tobacco smoke mediated induction of sinonasal microbial biofilms. PLoS One. 2011;6(1):e15700.

30. Antunes MB, Chi JJ, Liu Z, Goldstein-Daruech N, Palmer JN, Zhu J, et al. Molecular basis of tobacco-induced bacterial biofilms: an in vitro study. Otolaryngol Head Neck Surg. 2012;147(5):876-84

31. Bagaitkar J, Daep CA, Patel CK, Renaud DE, Demuth DR, Scott DA. Tobacco smoke augments Porphyromonas gingivalis - Streptococcus gordonii biofilm formation. PLoS One. 2011;6(11):e27386.

32. Kulkarni R, Antala S, Wang A, Amaral FE, Rampersaud R, Larussa SJ, et al. Cigarette smoke increases Staphylococcus aureus biofilm formation via oxidative stress. Infect Immun. 2012;80(11):3804-11.

33. Cockeran R, Herbert JA, Mitchell TJ, Dix-Peek T, Dickens C, Anderson R, et al. Exposure of a $23 \mathrm{~F}$ serotype strain of Streptococcus pneumoniae to cigarette smoke condensate is associated with selective upregulation of genes encoding the two-component regulatory system 11 (TCS11). Biomed Res Int. 2014;2014:976347.

34. Mutepe ND, Cockeran R, Steel HC, Theron AJ, Mitchell TJ, Feldman C, et al. Effects of cigarette smoke condensate on pneumococcal biofilm formation and pneumolysin. Eur Respir J. 2013;41(2):392-5.

35. Huang R, Li M, Gregory RL. Effect of nicotine on growth and metabolism of Streptococcus mutans. Eur J Oral Sci. 2012;120(4):319-25.

36. Baboni FB, Guariza Filho O, Moreno AN, Rosa EA. Influence of cigarette smoke condensate on cariogenic and candidal biofilm formation on orthodontic materials. Am J Orthod Dentofacial Orthop. 2010;138(4):427-34.

37. Grigg J, Walters H, Sohal SS, Wood-Baker R, Reid DW, Xu CB, et al. Cigarette smoke and platelet-activating factor receptor dependent adhesion of Streptococcus pneumoniae to lower airway cells. Thorax. 2012;67(10):908-13.

38. Teughels W, Van Eldere J, van Steenberghe D, Cassiman JJ, Fives-Taylor P, Quirynen M. Influence of nicotine and cotinine on epithelial colonization by periodontopathogens. J Periodontol. 2005;76(8):1315-22.
39. Benedetti G, Campus G, Strohmenger L, Lingström P. Tobacco and dental caries: a systematic review. Acta Odontol Scand. 2013;71(3-4):363-71.

40. Diaz PI. Microbial diversity and interactions in subgingival biofilm communities. Front Oral Biol. 2012;15:17-40.

41. Palmer RM, Wilson RF, Hasan AS, Scott DA. Mechanisms of action of environmental factors-tobacco smoking. J Clin Periodontol. 2005;32 Suppl 6:180-95.

42. Kumar PS, Matthews CR, Joshi V, de Jager M, Aspiras M. Tobacco smoking affects bacterial acquisition and colonization in oral biofilms. Infect Immun 2011;79(11):4730-8.

43. Zeller I, Hutcherson JA, Lamont RJ, Demuth DR, Gumus P, Nizam N, et al. Altered Antigenic Profiling and Infectivity of Porphyromonas Gingivalis in Smokers and Non-Smokers With Periodontitis. J Periodontol. 2014;85:837-44.

44. Shchipkova AY, Nagaraja HN, Kumar PS. Subgingival microbial profiles of smokers with periodontitis. J Dent Res. 2010;89(11):1247-53.

45. Morris A, Beck JM, Schloss PD, Campbell TB, Crothers K, Curtis JL, et al. Comparison of the respiratory microbiome in healthy nonsmokers and smokers. Am J Respir Crit Care Med. 2013;187(10):1067-75.

46. Fullmer SC, Preshaw PM, Heasman PA, Kumar PS. Smoking cessation alters subgingival microbial recolonization. J Dent Res. 2009;88(6):524-8.

47. Zambon JJ, Grossi SG, Machtei EE, Ho AW, Dunford R, Genco RJ. Cigarette smoking increases the risk for subgingival infection with periodontal pathogens. J Periodontol. 1996;67(10 Suppl):1050-4.

48. Haffajee AD, Socransky SS. Relationship of cigarette smoking to the subgingival microbiota. J Clin Periodontol. 2001;28(5):377-88.

49. Eggert FM, McLeod MH, Flowerdew G. Effects of smoking and treatment status on periodontal bacteria: evidence that smoking influences control of periodontal bacteria at the mucosal surface of the gingival crevice. J Periodontol. 2001;72(9):1210-20.

50. Kamma JJ, Nakou M, Baehni PC. Clinical and microbiological characteristics of smokers with early onset periodontitis. J Periodontal Res. 1999:34(1):25-33.

51. Grossi SG, Goodson JM, Gunsolley JC, Otomo-Corgel J, Bland PS, Doherty F, et al. Mechanical therapy with adjunctive minocycline microspheres reduces red-complex bacteria in smokers. J Periodontol. 2007;78(9):1741-50.

52. Bagaitkar J, Demuth DR, Daep CA, Renaud DE, Pierce DL, Scott DA. Tobacco upregulates $P$. gingivalis fimbrial proteins which induce TLR2 hyposensitivity. PLoS One. 2010;5(5):e9323.

53. Kuboniwa M, Amano A, Hashino E, Yamamoto $Y$, Inaba H, Hamada N, et al. Distinct roles of long/short fimbriae and gingipains in homotypic biofilm development by Porphyromonas gingivalis. BMC Microbiol. 2009;9:105.

54. Darveau RP, Arbabi S, Garcia I, Bainbridge B, Maier RV. Porphyromonas gingivalis lipopolysaccharide is both agonist and antagonist for p38 mitogen-activated protein kinase activation. Infect Immun. 2002;70:1867-73.

55. Buduneli N, Larsson L, Biyikoglu B, Renaud DE, Bagaitkar J, Scott DA. Fatty acid profiles in smokers with chronic periodontitis. J Dent Res. 2011;90:47-52.

\section{Submit your next manuscript to BioMed Central and take full advantage of:}

- Convenient online submission

- Thorough peer review

- No space constraints or color figure charges

- Immediate publication on acceptance

- Inclusion in PubMed, CAS, Scopus and Google Scholar

- Research which is freely available for redistribution 